\title{
Spontaneous regression of multiple pulmonary nodules in a patient with unclassified renal cell carcinoma following laparoscopic partial nephrectomy: A case report
}

\author{
KOSUKE UEDA, SHIGETAKA SUEKANE, TOMOTARO MITANI, KATSUAKI CHIKUI, KAZUHISA EJIMA, \\ SHUNSUKE SUYAMA, MAKOTO NAKIRI, KIYOAKI NISHIHARA, MITSUNORI MATSUO and TSUKASA IGAWA \\ Department of Urology, Kurume University School of Medicine, Kurume, Fukuoka 830-0011, Japan
}

Received November 9, 2015; Accepted March 24, 2016

DOI: $10.3892 / \operatorname{mco} .2016 .900$

\begin{abstract}
Spontaneous regression of metastatic renal cell carcinoma (RCC) is rare, but well-documented in clear cell RCC. However, there are no reports on spontaneous regression of unclassified RCC. Since the radiological findings of pulmonary infarcts and inflammatory pseudotumors are similar to those of metastases from RCC, a definitive diagnosis is difficult without performing a histological examination. A 56-year-old woman underwent medical examination by a physician. An abdominal computed tomography $(\mathrm{CT})$ scan revealed a $22-\mathrm{mm}$ mass with a cystic area in the right kidney, as well as multiple enlarged lymph nodes in the common iliac, external iliac and groin areas, bilaterally. A chest CT revealed multiple pulmonary nodules bilaterally, the largest measuring $15 \mathrm{~mm}$. Since the right renal tumor was suspected to be an RCC, laparoscopic partial nephrectomy was performed. The final pathological diagnosis of the renal tumor was unclassified RCC. One month following surgery, a CT scan revealed spontaneous regression of the pulmonary nodules. We herein present a rare case of spontaneous regression of pulmonary nodules in a patient with unclassified RCC following laparoscopic partial nephrectomy. To the best of our knowledge, this is the first case of spontaneous regression in unclassified RCC.
\end{abstract}

\section{Introduction}

Unclassified renal cell carcinoma (RCC) does not belong to a specific RCC subtype with unique diagnostic histological findings or characteristic genetic changes. The frequency of this

Correspondence to: Dr Kosuke Ueda, Department of Urology, Kurume University School of Medicine, 67 Asahi-Machi, Kurume, Fukuoka 830-0011, Japan

E-mail: ueda_kousuke@med.kurume-u.ac.jp

Key words: renal cell carcinoma, unclassified, spontaneous regression, metastasis, kidney cancer type of RCC is quite variable, accounting for $0.7-5.7 \%$ of all RCCs (1). Previous reports suggested that unclassified RCC is associated with unfavourable histological characteristics and aggressive behavior $(1,2)$.

Spontaneous regression of metastases of RCC is rare, but well-documented in the course of clear cell RCC. However, there are no reports on spontaneous regression of unclassified $\mathrm{RCC}$ to date. We herein present the rare case of spontaneous regression of pulmonary nodules in a patient with unclassified RCC following laparoscopic partial nephrectomy.

\section{Case report}

A 56-year old woman underwent medical examination by a physician. The patient was asymptomatic prior to hospitalization. Computed tomography (CT) was performed. Abdominal $\mathrm{CT}$ revealed a 22-mm mass with a cystic area in the right kidney and multiple enlarged lymph nodes in the common iliac, external iliac and groin areas bilaterally (Fig. 1A and B). The chest CT revealed multiple pulmonary nodules bilaterally, the largest measuring $15 \mathrm{~mm}$ (Fig. $1 \mathrm{C}$ and D). The laboratory tests revealed mild elevation of the C-reactive protein levels to $1.16 \mathrm{mg} / \mathrm{dl}$ (normal range, $\leq 0.14 \mathrm{mg} / \mathrm{dl}$ ). The levels of tumor markers, such as squamous cell carcinoma antigen, carbohydrate antigen 19-9, carcinoembryonic antigen (CEA), cytokeratin 19 fragment and pro-gastrin-releasing peptide, were within the normal range. The serum concentration of soluble interleukin-2 receptor (sIL-2R) was increased to $914 \mathrm{U} / \mathrm{ml}$ (reference range, 122-496 U/ml). [ $\left.{ }^{18} \mathrm{~F}\right]$ 2-fluoro-2deoxy-d-glucose $\left({ }^{18} \mathrm{~F}-\mathrm{FDG}\right)$ positron emission tomography showed high FDG uptake by multiple enlarged lymph nodes, whereas the right kidney mass and the pulmonary nodules exhibited no increased uptake. A right inguinal lymph node biopsy was first performed, since malignant lymphoma was suspected. On microscopic examination, there were sheets of lymphoid cells and numerous lymphoid follicles; however, there was no evidence of tumor cells (Fig. 2) and the lymph node enlargement was diagnosed as reactive lymphoid hyperplasia. Since the right renal tumor was suspected to be RCC, laparoscopic partial nephrectomy was performed, without any complications. The resected tumor was sized $25 \mathrm{~mm}$ and was well-circumscribed; histologically, it was composed of cells 

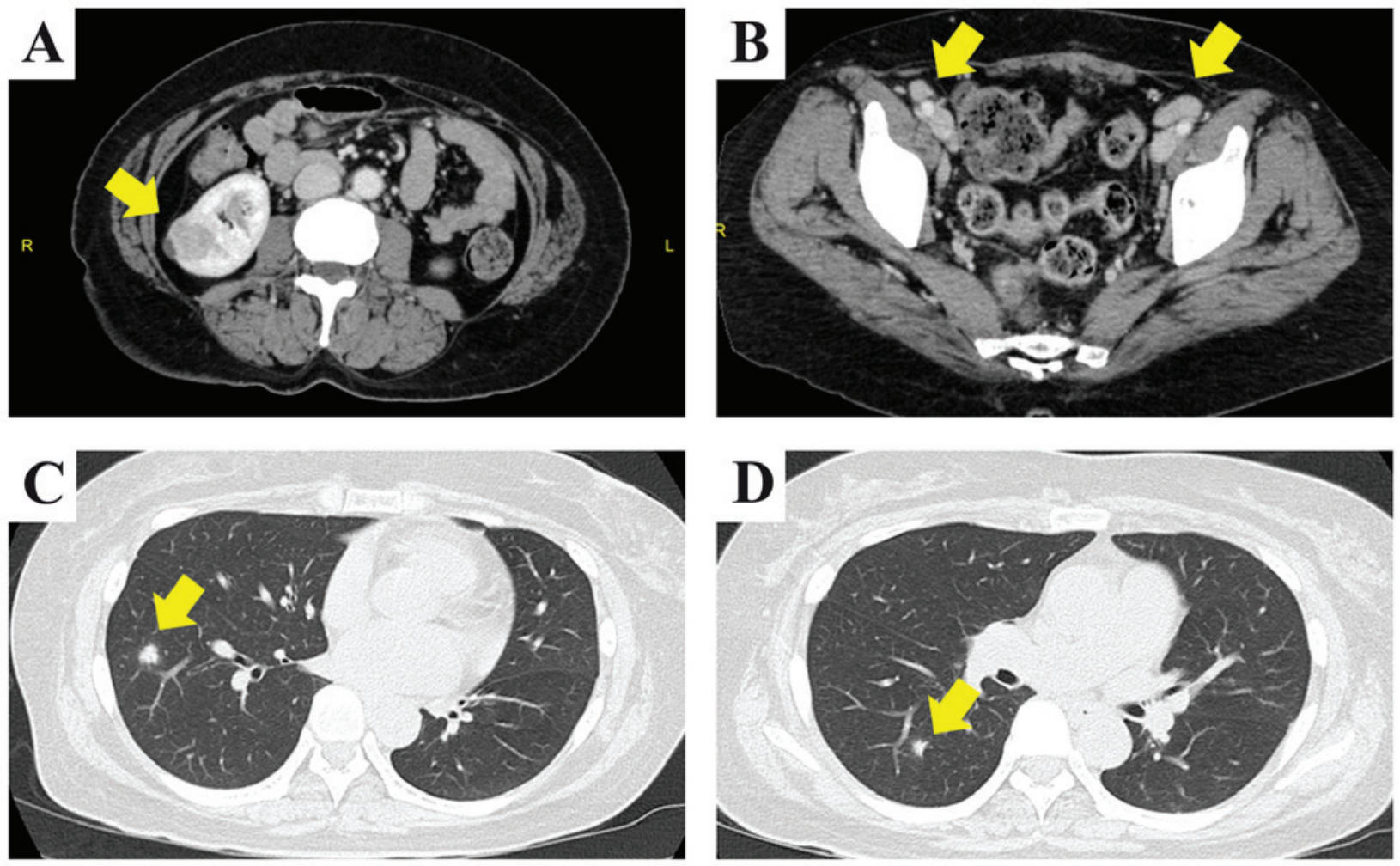

Figure 1. (A-D) Computed tomography (CT) scan findings at diagnosis of this case. (A) Abdominal CT revealed a 22-mm enhanced mass with a cystic area in the right kidney (arrow), with (B) multiple enlarged lymph nodes in the common iliac, external iliac and groin areas, bilaterally (arrows). (C and D) Thoracic CT scan revealed several nodules with a maximum diameter of $15 \mathrm{~mm}$ in the lung (arrows).

with eosinophilic cytoplasm arranged in glandular and cribriform patterns (Figs. 3 and 4). Immunohistochemically, almost all the tumor cells were diffusely positive for pancytokeratin (AE1/AE3), cytokeratin 7 and E-cadherin. Immunoreactivity for CD10, $\alpha$-methylacyl-CoA racemase, 34ßE12, c-kit, anaplastic lymphoma kinase, thyroid transcription factor-1, p63 and CEA was not detected in the tumor cells. These findings suggested that the tumor was a RCC with distal tubular characteristics. However, the findings were not typical. The case was referred for expert consultation, and the final pathological diagnosis was unclassified RCC. One month after surgery, a thoracic CT scan revealed spontaneous regression of the pulmonary nodules (Fig. 5). However, the enlargement of the lymph nodes did not subside. Surveillance CT scans at 3 months revealed no evidence of recurrence or progression of the pulmonary nodules and lymph nodes. In addition, the level of sIL-2R had decreased to $511 \mathrm{U} / \mathrm{ml}$.

\section{Discussion}

RCC accounts for $3 \%$ of all cancers and its incidence is steadily increasing. RCC is the most common among renal tumors in adults, accounting for $85 \%$ of neoplasms arising in the kidney (3). Approximately one-fourth of RCC patients are known to have metastatic disease at the initial diagnosis (4). The lungs (50\%), bones (49\%), lymph nodes (6-32\%), skin (11\%), liver (8\%) and brain (3\%) are the most frequent sites of clinical metastases (5), and these patients generally have a poor prognosis, with a reported 5-year survival of $3-11 \%$ for unoperated patients (6).

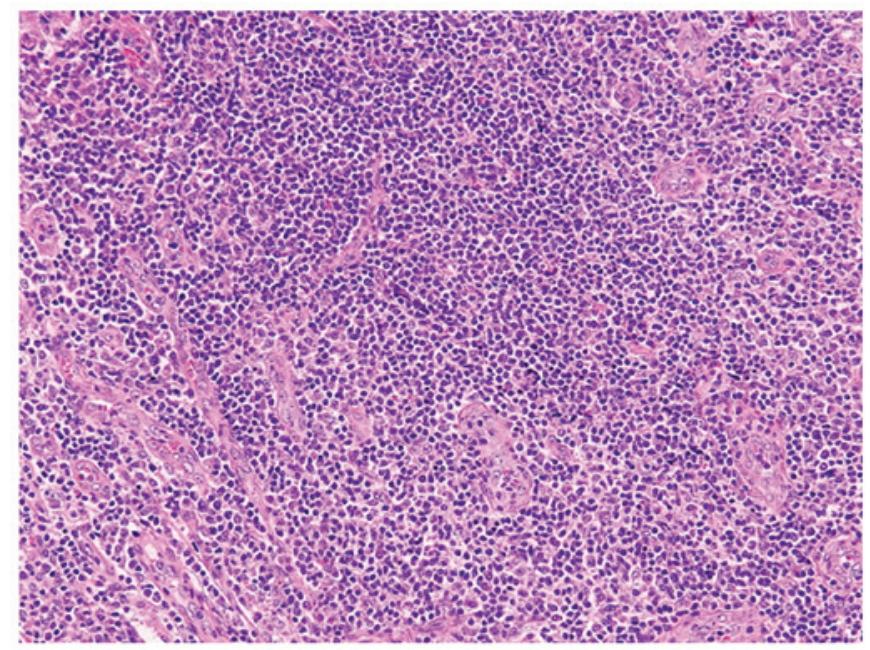

Figure 2. Microscopic appearance of biopsy specimen from a right inguinal lymph node. Sheets of lymphoid cells and numerous lymphoid follicles were identified. However, there was no evidence of malignancy (hematoxylin and eosin staining; magnification, $\mathrm{x} 100$ ).

In the era of immunotherapy, cytoreductive nephrectomy followed by interferon- $\alpha$ treatment increased overall survival (OS) in RCC patients compared with immunotherapy alone $(7,8)$. In this era of molecular-targeted therapy, it was also reported that cytoreductive nephrectomy may provide an OS benefit in patients with metastatic RCC (9).

Spontaneous regression of metastases in RCC is rare, occurring in $<1 \%$ of all cases (10). In 1928, Bumpus described the first reported case of spontaneous regression of metastatic 


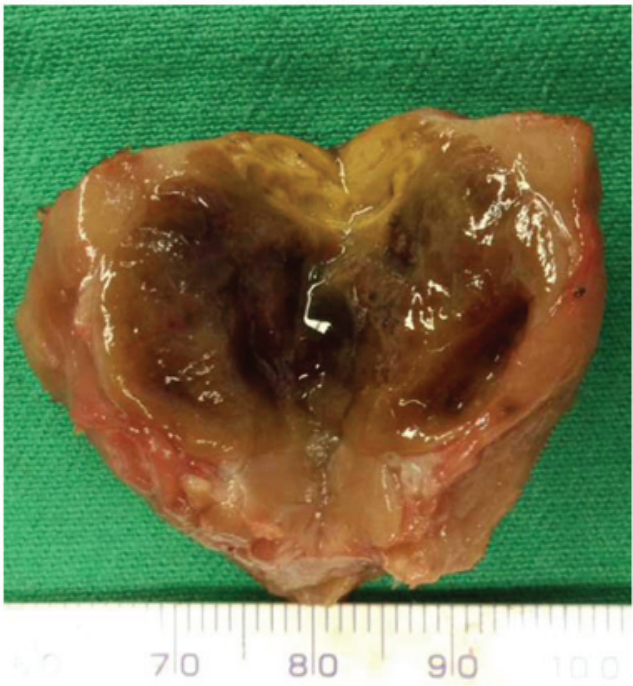

Figure 3. Macroscopic appearance of the resected right renal mass. The tumor was sized $25 \mathrm{~mm}$ and was well-circumscribed.

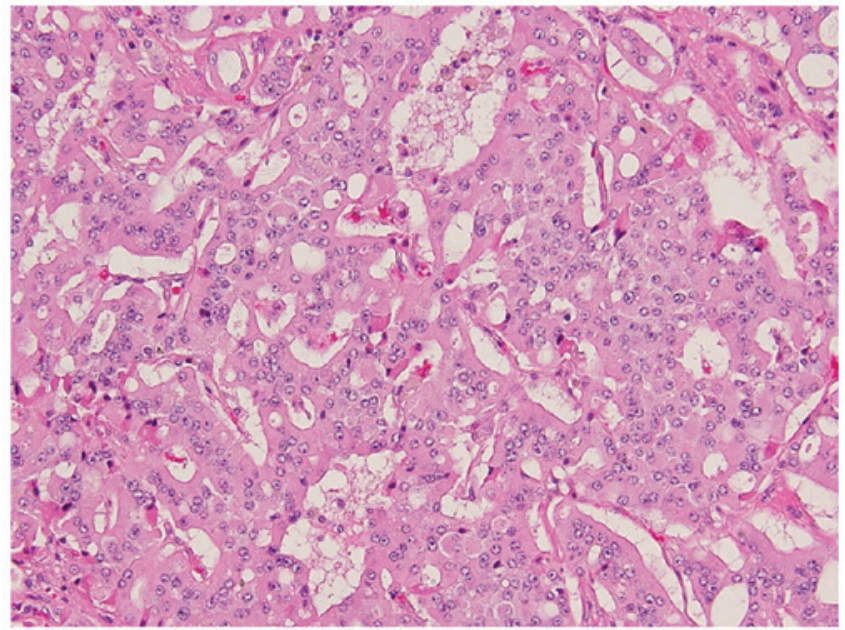

Figure 4. Microscopic appearance of the right renal tumor. The tumor was composed of cells with eosinophilic cytoplasm, arranged in glandular and cribriform patterns (hematoxylin and eosin staining; magnification, x100).

RCC (11). It was previously reported that a number of these cases are associated with surgical removal of the primary tumor, but regression may also occur in association to radiation or embolization of the primary tumor (12). Different hypotheses of this rare phenomenon have been documented. The suggested mechanism of spontaneous regression is considered to be an immune response, which may be evoked by surgery, tumor necrosis, infection, radiotherapy and other treatments $(13,14)$. In our case, spontaneous regression of multiple pulmonary nodules was observed following nephrectomy. Malignant lymphoma was first suspected on preoperative assessment, due to multiple lymph node enlargement and the increased sIL-2R level. However, histopathological examination of a lymph node biopsy specimen revealed reactive lymphoid hyperplasia, while the renal tumor was diagnosed as RCC. It has been reported that pulmonary infarcts caused by, e.g., emboli, may mimic pulmonary metastases on radiographic scans $(15,16)$. Several reports have also demonstrated
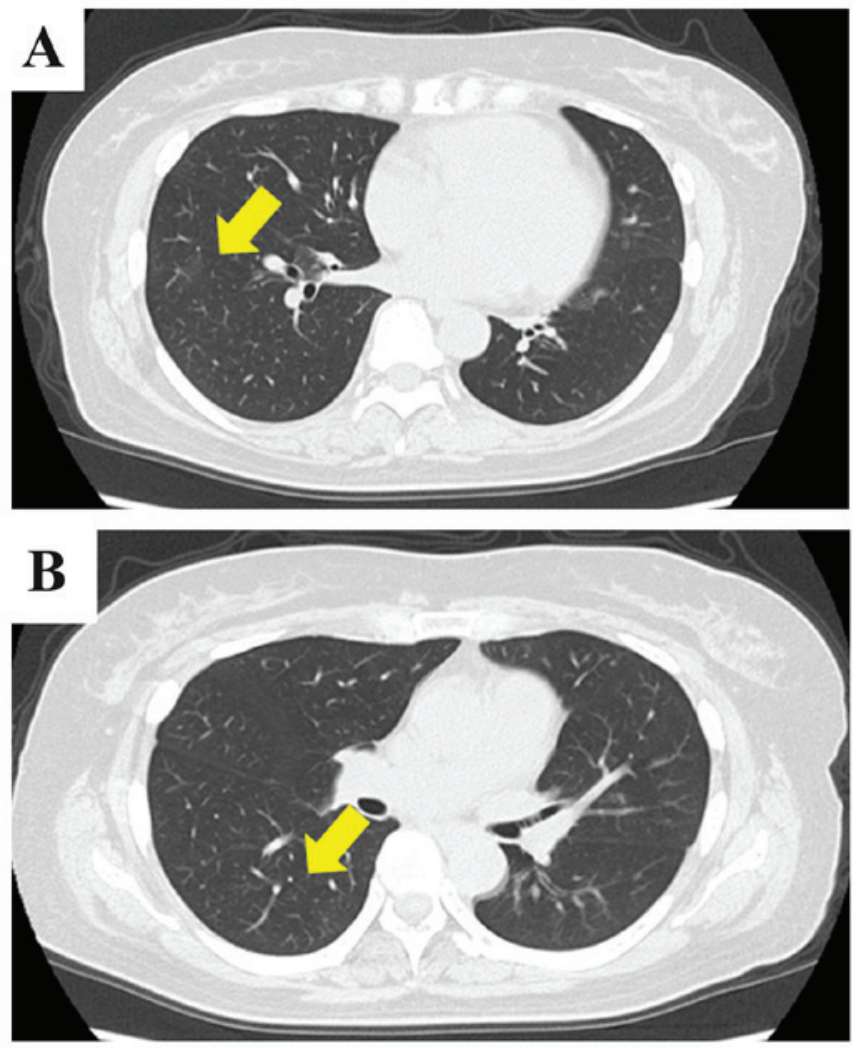

Figure 5. (A and B) Thoracic computed tomography scan showing spontaneous regression of multiple pulmonary nodules compared with Fig. 1 (arrows).

that IgG4-related diseases and Epstein-Barr virus-associated lymphoproliferative diseases occasionally cause inflammatory pseudotumors (17-19). The examinations of these diseases revealed contradictory findings.

Previous reports demonstrated that the majority of unclassified RCCs are aggressive, mainly because in the majority of the cases they are at an advanced stage at presentation $(1,2)$. Our patient has a good clinical course, without disease recurrence or progression. Most previous reports of spontaneous regression were of clear cell RCC. To the best of our knowledge, this is the first case of spontaneous regression of pulmonary nodules in a patient with unclassified RCC following partial nephrectomy. However, the main limitation of this study is the lack of histological confirmation from the pulmonary nodules in our case. Adequate histological confirmation of metastases has been estimated to be available in only $20 \%$ of cases with spontaneous regression (20). Although there is no evidence of the pulmonary nodules being metastatic in our case, this clinical phenomenon is rare in unclassified RCC. As regards disease recurrence, long-term follow-up is required.

\section{References}

1. Lopez-Beltran A, Kirkali Z, Montironi R, Blanca A, Algaba F, Scarpelli M, Yorukoglu K, Hartmann A and Cheng L: Unclassified renal cell carcinoma: A report of 56 cases. BJU Int 110: 786-793, 2012.

2. Karakiewicz PI, Hutterer GC, Trinh QD, Pantuck AJ, Klatte T, Lam JS, Guille F, de La Taille A, Novara G, Tostain J, et al: Unclassified renal cell carcinoma: An analysis of 85 cases. BJU Int 100: 802-808, 2007. 
3. Landis SH, Murray T, Bolden S and Wingo PA: Cancer statistics, 1999. CA Cancer J Clin 49: 8-31.1, 1999.

4. Hock LM, Lynch J and Balaji KC: Increasing incidence of all stages of kidney cancer in the last 2 decades in the United States: An analysis of Surveillance, Epidemiology and End Results program data. J Urol 167: 57-60, 2002.

5. Pagano S, Franzoso F and Ruggeri P: Renal cell carcinoma metastases. Review of unusual clinical metastases, metastatic modes and patterns and comparison between clinical and autopsy metastatic series. Scand J Urol Nephrol 30: 165-172, 1996.

6. Kavolius JP, Mastorakos DP, Pavlovich C, Russo P, Burt ME and Brady MS: Resection of metastatic renal cell carcinoma. J Clin Oncol 16: 2261-2266, 1998.

7. Flanigan RC, Salmon SE, Blumenstein BA, Bearman SI, Roy V, McGrath PC, Caton JR Jr, Munshi N and Crawford ED: Nephrectomy followed by interferon alfa- $2 b$ compared with interferon alfa-2b alone for metastatic renal-cell cancer. $N$ Engl J Med 345: 1655-1659, 2001.

8. Mickisch GH, Garin A, van Poppel H, de Prijck L and Sylvester R; European Organisation for Research and Treatment of Cancer (EORTC) Genitourinary Group: Radical nephrectomy plus interferon-alfa-based immunotherapy compared with interferon alfa alone in metastatic renal-cell carcinoma: A randomised trial. Lancet 358: 966-970, 2001

9. Heng DY, Wells JC, Rini BI, Beuselinck B, Lee JL, Knox JJ, Bjarnason GA, Pal SK, Kollmannsberger CK, Yuasa T, et al: Cytoreductive nephrectomy in patients with synchronous metastases from renal cell carcinoma: Results from the International Metastatic Renal Cell Carcinoma Database Consortium. Eur Urol 66: 704-710, 2014.

10. de Riese W, Goldenberg K, Allhoff E, Stief C, Schlick R, Liedke S and Jonas U: Metastatic renal cell carcinoma (RCC): Spontaneous regression, long-term survival and late recurrence. Int Urol Nephrol 23: 13-25, 1991.

11. Bumpus HC: The apparent disappearance of pulmonary metastasis in a case of hypernephroma following nephrectomy. J Urol 20: 181-191, 1928.
12. Lokich J: Spontaneous regression of metastatic renal cancer. Case report and literature review. Am J Clin Oncol 20: 416-418, 1997.

13. Ishiyama $\mathrm{H}$, Teh BS, Ren $\mathrm{H}$, Chiang S, Tann A, Blanco AI, Paulino AC and Amato R: Spontaneous regression of thoracic metastases while progression of brain metastases after stereotactic radiosurgery and stereotactic body radiotherapy for metastatic renal cell carcinoma: Abscopal effect prevented by the blood-brain barrier? Clin Genitourin Cancer 10: 196-198, 2012.

14. Ricci SB and Cerchiari U: Spontaneous regression of malignant tumors: Importance of the immune system and other factors (Review). Oncol Lett 1: 941-945, 2010.

15. Janiszewska AD, Poletajew S and Wasiutyński A: Spontaneous regression of renal cell carcinoma. Contemp Oncol (Pozn) 17: 123-127, 2013.

16. Wagner JR, Merino MJ, Pass HI, Linehan WM and Walther MM: Pulmonary infarcts can mimic pulmonary metastases from renal cancer. J Urol 158: 1688-1690, 1997.

17. Miura H and Miyachi Y: IgG4-related retroperitoneal fibrosis and sclerosing cholangitis independent of autoimmune pancreatitis. A recurrent case after a 5-year history of spontaneous remission. JOP 10: 432-437, 2009.

18. McCabe MG, Hook CE and Burke GA: Spontaneous regression of an EBV-associated monoclonal large B-cell proliferation in the mastoid of a young child following surgical biopsy. Pediatr Blood Cancer 51: 557-559, 2008.

19. Park SH, Kim CG, Kim JY and Choe JY: Spontaneous regression of EBV-associated diffuse lymphoproliferative disease in a patient with rheumatoid arthritis after discontinuation of etanercept treatment. Rheumatol Int 28: 475-477, 2008.

20. Chan BP, Booth CM, Manduch M and Touma NJ: Spontaneous regression of metastatic pulmonary renal cell carcinoma in the setting of sarcomatoid differentiation of the primary tumour. Can Urol Assoc J 7: E587-E589, 2013. 